\title{
Thermal characterization of thermoplastic composites under high temperature and fire by infrared imaging
}

Juan Meléndez, Daniel Benito, Alba López-Béjar, Javier Talavante, Susana Briz, et al.

Juan Meléndez, Daniel Benito, Alba López-Béjar, Javier Talavante, Susana Briz, Antonio J. de Castro, Fernando López, "Thermal characterization of thermoplastic composites under high temperature and fire by infrared imaging," Proc. SPIE 11743, Thermosense: Thermal Infrared Applications XLIII, 1174300 (12 April 2021); doi: 10.1117/12.2585799 


\title{
Thermal characterization of thermoplastic composites under high temperature and fire by infrared imaging
}

\author{
Juan Meléndez, Daniel Benito, Alba López-Béjar, Javier Talavante, Susana Briz, Antonio J. de \\ Castro and Fernando López \\ LIR - Infrared Laboratory, Department of Physics \\ Universidad Carlos III de Madrid, 28911 Leganés, Spain
}

\begin{abstract}
In the last decades, composite materials, particularly thermosetting carbon fiber reinforced polymers, have become the main structural material for the aerospace industry. Recently, interest has grown in thermoplastic composites, since they are chemically more stable, faster to process, fatigue-resistant and recyclable. Nevertheless, when submitted to high temperatures these materials may degrade in ways not presently well known. Therefore, the study of the thermo-mechanical properties of thermoplastic composites when exposed to fire or high-temperature events is of primary interest. In particular, a good knowledge of its behavior could improve physical modeling to the point of reducing the number of prescribed fire tests by virtualizing some of them. The first step is to measure the thermal parameters of real samples in a practical way. We have established a methodology that extends the classical flash method to obtain the effective thermal parameters (diffusivity, specific heat, heat conductivity, and Biot number) of thermoplastic composite materials by a non-contact method based on IR imaging. Values obtained have been used to simulate thermal behavior with a FEM-based solver, from room temperature up to $900^{\circ} \mathrm{C}$, with an agreement with experimental data better than $1 \%$ in temperature (K) for temperatures below $\sim 260^{\circ} \mathrm{C}$ and better than $3 \%$ up to $\sim 850^{\circ} \mathrm{C}$.
\end{abstract}

Keywords: Infrared imaging, Thermography, Fire, Fire test, Thermal diffusivity, Composite materials

\section{INTRODUCTION}

The predominant materials in aerospace manufacturing used to be aluminum, steel, and titanium, which accounted for up to $70 \%$ of the typical aircraft. However, with the growing demand for weight reduction, better fuel economy, and lower operation costs, metals are losing ground in the airframe composition to composite materials, which are lighter and resistant to corrosion and fatigue.

Additionally, the sector is making a transition to a more electric aircraft, increasing the thermal vulnerability of the structure because the number of potential heat and fire sources increases: new equipment that may cause overheating and accidentally cause a fire is being required (batteries, EHA and EMA actuators, ice protection, e-braking and taxiing) while traditional heat sources and hazards (bleeding tubes, nozzle exhausts, engine and APU, fuel system) still remain. This trend is a potential challenge for the expansion of the use of composite materials, since the application of fire or high temperatures may induce serious damage in them. Degradation includes polymeric matrix decomposition and melting, growth of voids, the formation of bubbles with gases inside and other structural damages that may cause the loss of mechanical resistance and finally, under loading or after enough time, mechanical failure. ${ }^{1}$

One of the aims of the Airframe Integrated Technology Demonstrator of the Clean Sky Joint Undertaking of the European Commission and the European aeronautics industry, funded by the Horizon 2020 initiative, is to achieve lighter and more cost-effective structures by increasing the structural contribution of more efficient composites. Under this framework, the research project HITCOMP ${ }^{2}$ aims to characterize the behavior, under fire and thermal affection, of new high-performance thermoplastic composites based on Poliaryletherketone (PAEK) family resins. These promising materials show some advantages over the current widely used thermoset composites based on epoxy resins, including good chemical resistance to acids, alkali, and organic solvents; ${ }^{3}$ elevated temperatures for glass transition $\left(T_{g} \approx 143^{\circ} \mathrm{C}\right)$ and fusion $\left(T_{m} \approx 343-380^{\circ} \mathrm{C}\right) ;{ }^{1,4}$ low heat release rate and small smoke emission when burned. ${ }^{1}$ In addition, they retain useful mechanical properties well above their

Thermosense: Thermal Infrared Applications XLIII, edited by Joseph N. Zalameda, Proc. of SPIE Vol. $11743,1174300 \cdot$ C 2021 SPIE · CCC code: 0277-786X/21/\$21 doi: 10.1117/12.2585799 
$T_{g}$, with a continuous service temperature $(\mathrm{CST})$ of $\approx 250^{\circ} \mathrm{C} .{ }^{3}$ These properties make them very well suited for high-temperature applications, specifically in fire-prone or thermally demanding areas of the structure such as nacelle compartments, movable surfaces affected by engine nacelle exhaust, or any other area of the structure affected by hot air exhaust impact.

On the other hand, the detailed properties of thermoplastic composites are not yet well known, and for that reason a large number of tests should be done to complete their thermomechanical characterization. The most popular methods for composite characterization under fire are those based on calorimetric cones, since they allow controlling all the boundary conditions, but the more informative and realistic are fire tests, in which a sample of the material is exposed to a calibrated flame. However, these tests are destructive, expensive, and cumbersome to perform, and so it would be highly desirable to minimize their number, by maximizing the information obtained from each of them. In this work, we employ an innovative measurement setup, previously developed, ${ }^{5}$ for the fire test. Using two co-registered IR cameras, it provides accurate, non-intrusive measurements of the actual temperature distribution at both faces of the sample, as a function of time, in the real test conditions. This information, together with values of thermal parameters obtained with an adapted flash method, ${ }^{5,6}$ is used by a thermo-mechanical finite-element model (FEM) to simulate the behavior of the material. The comparison of simulation and experimental measurements allows for the adjustment and validation of the model. The final aim is to reduce the cost in money and time of thermal characterization of thermoplastics, by being able to "virtualize" at least some of the tests and to predict their behavior and resistance when submitted to fire or high-temperature events. In the long run, this should make it possible to forecast the time to failure for a determined specimen of a thermoplastic composite material submitted to fire, with any number of layers, thickness, specific attachment, airflow rate in the cold face, mechanical load, etc.

In this paper, Section 2 reviews the basic principles of thermal characterization by a modified flash method that takes into account thermal losses and shows the results obtained in the samples studied as well as their validation by means of step-heating tests. It is found that behavior at temperatures above $\sim 150^{\circ} \mathrm{C}$ cannot be well reproduced with the room temperature parameters, and thus the effect of exposure to high temperatures on the thermal parameters is studied in Section 3, by heating samples in a furnace. Characterization at room temperature finds no changes for furnace heating up to $\sim 450^{\circ} \mathrm{C}$, which is interpreted as evidence of reversibility of the temperature-induced changes below that temperature in thermoplastic materials, as opposed to the irreversible behavior of thermosettings. The study of samples under real fire conditions becomes therefore essential, and is carried out in Section 4, which describes the experimental measurements and results provided by the two-cameras measurement setup. These results have been reproduced by a FEM model in Section 5 . The model proposes a dependence of effective thermal parameters with temperature, which is validated by the good fitting of the experimental results. Finally, 6 summarizes the paper and draws the conclusions of this work.

\section{THERMAL CHARACTERIZATION OF THERMOPLASTIC MATERIALS AT ROOM TEMPERATURE}

\subsection{Flash test}

The thermal parameters of the thermoplastic material at room temperature have been obtained by application of the flash test. This well-known technique of thermal characterization is based on the analysis of the time evolution of temperature at the rear face of a flat sample when it is heated by a very short and intense pulse of radiation at the front face. It was first developed by Parker et $\mathrm{al}^{7}$ to measure diffusivity $\alpha\left[\mathrm{m}^{2} / \mathrm{s}\right]$ for specimens in which heat losses are negligible (Biot number $B i \approx 0$ ).

Diffusivity and Biot number are defined as

$$
\begin{aligned}
\alpha & =\frac{\kappa}{\rho \cdot c_{p}} \\
B i & =\frac{h \cdot L}{\kappa}
\end{aligned}
$$

where $\kappa[\mathrm{W} / \mathrm{m} \cdot \mathrm{K}]$ is the thermal conductivity, $\rho\left[\mathrm{kg} / \mathrm{m}^{3}\right]$ the density, $c_{p}[\mathrm{~J} / \mathrm{kg} \cdot \mathrm{K}]$ the specific heat, $h\left[\mathrm{~W} / \mathrm{m}^{2} \cdot \mathrm{K}\right]$ the heat transfer coefficient and $L[\mathrm{~m}]$ the sample thickness. 
Degiovanni ${ }^{8}$ and other authors extended the flash method for the general case of non-negligible heat losses by proving that, if a normalized temperature increase $\left(T^{*}\right)$ and a dimensionless time $\left(t^{*}\right)$ are defined by

$$
\begin{gathered}
t^{*}=\frac{t \cdot \alpha}{L^{2}} \\
T^{*}=\frac{T-T_{a m b}}{T_{\max }-T_{a m b}}
\end{gathered}
$$

then for each Biot number there is a unique $T^{*}\left(t^{*}\right)$ function with a well-known analytical expression. Therefore, $B i$ and $\alpha$ can be obtained by fitting the $T^{*}$ vs $t^{*}$ experimental profile with the $T^{*}\left(t^{*}\right)$ function calculated numerically. ${ }^{6}$ Figure 1 shows the time evolution of $T^{*}$ vs $t^{*}$ in two flash experiments for specimens of two different thicknesses (1.5 and $4.5 \mathrm{~mm}$ ), together with the fitting analytical function.
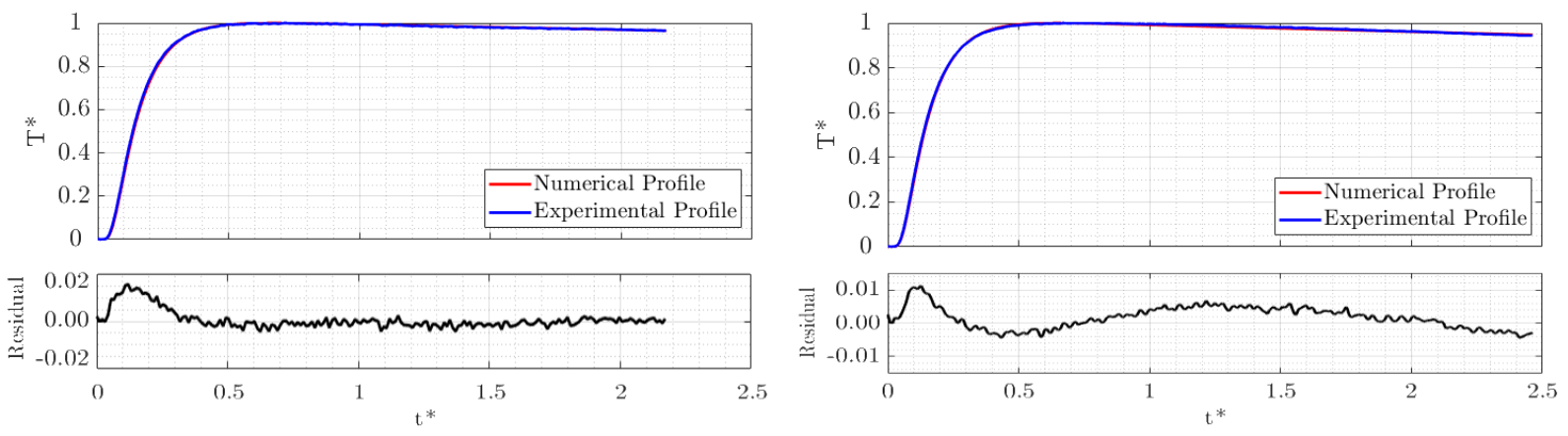

Figure 1: Flash test experimental temperature profiles and theoretical fittings for two specimens in a flash test. (Left) Specimen $1.5 \mathrm{~mm}$ thick, $T_{\max }-T_{a m b}=3.56^{\circ} \mathrm{C}$; the lamp was placed at $20 \mathrm{~cm}$ from the sample. (Right) Specimen 4.5 mm thick, $T_{\max }-T_{a m b}=3.64^{\circ} \mathrm{C}$; the lamp was placed at $10 \mathrm{~cm}$ from the sample.

Once $B i$ and $\alpha$ have been determined, thermal conductivity can be obtained from equation (1) if the volumetric heat capacity $\rho \cdot c_{p}$ is known. If there were no heat losses and the heat density $Q\left[\mathrm{~J} / \mathrm{m}^{2}\right]$ supplied by the lamp were known, $\rho \cdot c_{p}$ could be solved from

$$
Q=\rho \cdot c_{p} \cdot L \cdot\left(T_{l i m}-T_{a m b}\right)
$$

where $T_{\text {lim }}$ is the uniform temperature of the sample when $t \rightarrow \infty$. In a real sample, heat losses imply that $T_{\text {lim }}$ is not reached, but its value can be calculated from the maximum temperature at the rear of the sample $T_{\max }$ and the Biot number. ${ }^{5,6}$ Thus, using a lamp with known $Q$ makes it possible to find $\rho \cdot c_{p}$ and therefore $\kappa$.

This procedure has been applied to five specimens of thermoplastic composite, three of them with $L=1.5 \mathrm{~mm}$ and two with $L=4.5 \mathrm{~mm}$, with the same nominal composition. There were no significant differences between the parameters of the samples of different thicknesses. The (mean \pm standard deviation) measured values were $\alpha=(5.6 \pm 0.1) \cdot 10^{-7} \mathrm{~m}^{2} / \mathrm{s}, \rho \cdot c_{p}=(1.36 \pm 0.05) \cdot 10^{6} \mathrm{~J} / \mathrm{m}^{3} \mathrm{~K}$ and $\kappa=0.77 \pm 0.04 \mathrm{~W} / \mathrm{m} \cdot \mathrm{K}$.

\subsection{Validation of parameters: Step test}

In order to validate the thermal parameters previously obtained, a different procedure is used: the step test. A ceramic radiant heater is applied close to the specimen front face (Figure 2, left) and keeps heating it until a steady state is reached. To obtain a sharp start of the heating (square-like pulse), an insulating screen is placed between the heater and specimen and abruptly removed when the heater is stabilized. Temperature maps of both front and back face (Figure 2, right) are recorded and co-registered in space and time.

The time evolution of the measured temperature in the rear face is compared to the result of a finite element method (FEM) simulation, that uses as input the thermal parameters obtained from the flash test and the measured temperature the front face as a function of time. Figure 3 shows experimental and simulated profiles from the first step test performed, on the sample with thickness $1.5 \mathrm{~mm}$. In this experiment, the agreement 

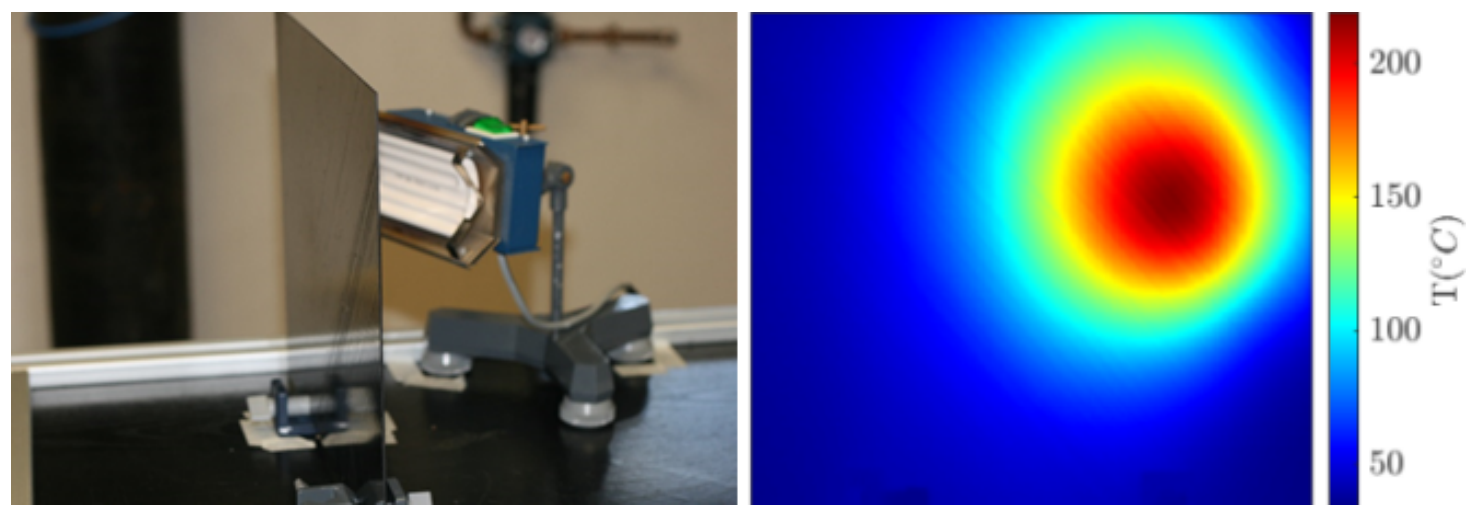

Figure 2: (Left) Setup for step test. (Right) Thermal map of the rear face at the stationary stage in a step test.

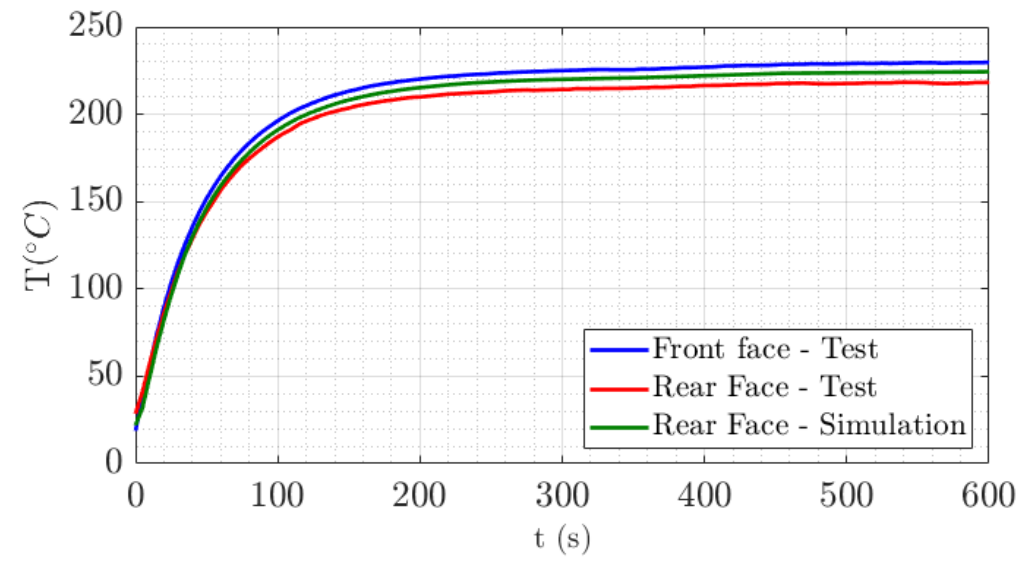

Figure 3: Step test experimental and simulated temperature results using room temperature thermal parameters. The mismatch observed is due to the variation of thermal parameters with temperature.

between the simulated and experimental profiles gets worse as the temperature of the front face increases. This suggests that the lack of agreement can be due to the variation of thermal parameters with temperature.

A new step test was carried out with a different heat source so that temperatures of the sample were kept relatively low. Figure 4 shows that in this case the relative error in temperature between the experimental and simulated profiles is kept very small, being always less than $1 \%$ in $\mathrm{K}$. These results validate the thermal parameters obtained for moderate temperatures $\left(<150^{\circ} \mathrm{C}\right)$. Therefore a first critical temperature $T_{c 1}$ is established tentatively at $\approx 150^{\circ} \mathrm{C}$, a value which is in the range of the glass transition temperature $T_{g}$. Assuming a degradation of the thermal parameters above $T_{c 1}$ makes possible to achieve a much better agreement with the experimental results, as will be explained in Section 5 .

\section{FURNACE TEST}

After the flash tests of virgin material just described, the effect of temperature on the samples was tested by uniform heating the specimens in a furnace. When thermal equilibrium was reached at a prescribed temperature, the samples were allowed to cool down at room temperature and the thermal parameters were obtained using the flash technique. A maximum furnace temperature of $500^{\circ} \mathrm{C}$ was reached. Figure 5 shows the results for $\alpha \mathrm{y}$ $\kappa$ in a sample for the different furnace temperatures used.

Thermal properties measured at room temperature show no appreciable degradation even in samples heated up to $\sim 450^{\circ} \mathrm{C}$ in the furnace. This result was not expected on the basis of our previous experience with fire tests of thermosetting materials, where two critical temperatures appear. First, the material begins to change 

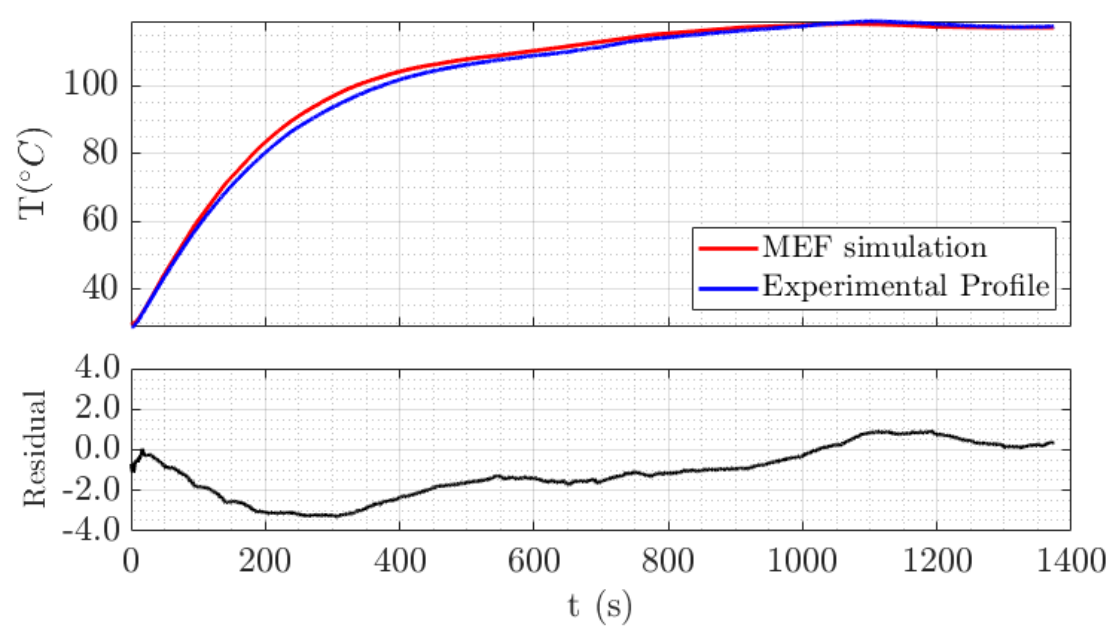

Figure 4: Comparison between experimental and simulated temperature profile of a step test under $150{ }^{\circ} \mathrm{C}$. The correlation along the duration of the experiment is good enough and the maximum error is close to $1 \%$ in $\mathrm{K}$.
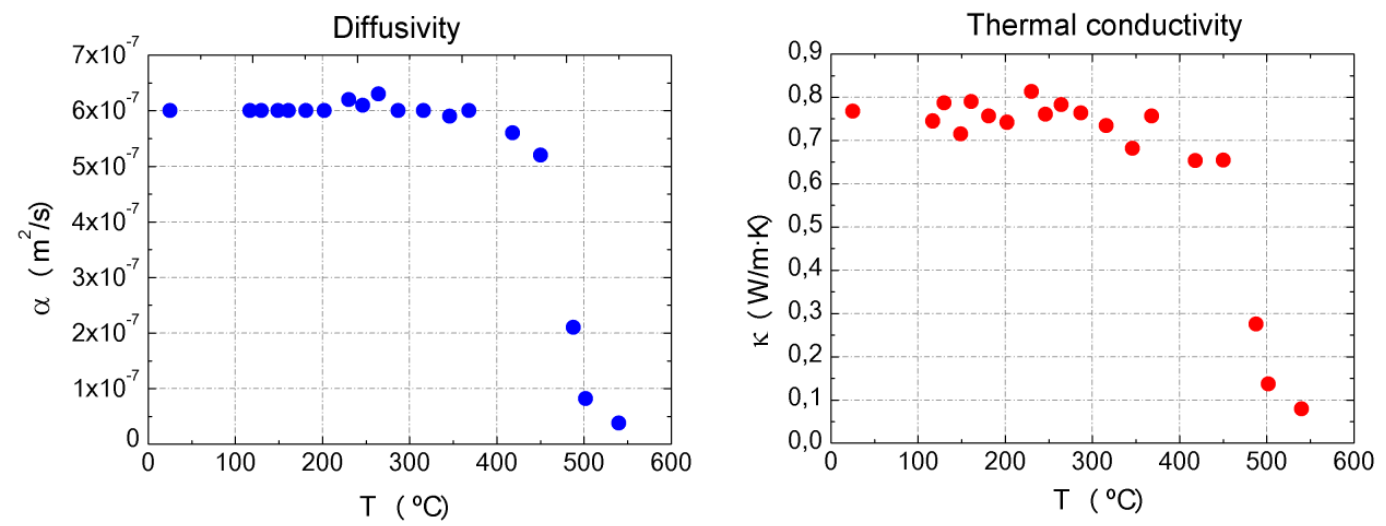

Figure 5: Diffusivity (left) and conductivity (right) of thermopastic samples measured by flash method at room temperature after heating in a furnace, as a function of the furnace temperature.

its thermal properties and to drop its mechanical strength and stiffness (leading to failure if large loads are applied) between $\sim 280^{\circ} \mathrm{C}$ and $\sim 300^{\circ} \mathrm{C}$ depending on the specific material. This critical temperature $\left(T_{c 1}\right)$ that corresponds approximately to the glass transition temperature, $T_{g}$, of thermosets. Then, at around $350-360^{\circ} \mathrm{C}$ or even higher temperatures $\left(T_{c 2}\right)$, the polymeric matrix becomes fully degraded into volatiles and char. Thereafter, only the fibers survive, and the material can be assimilated to a loose fabric.

For thermoplastic materials, the behavior was expected to be similar below $T_{g}$ but different above, with an additional drop of the Young modulus ${ }^{9}$ at temperatures above $T_{c 1}$, but requiring higher temperatures, near $500^{\circ} \mathrm{C}$ to achieve full degradation with chemical decomposition. ${ }^{10}$ The fact that no critical temperatures are found in these experiments below that temperature range may be explained if thermal changes do take place during heating above $150^{\circ} \mathrm{C}$, but they are reversible and thus the material, when cooled to room temperature, does not show appreciable changes. This reversible behavior is quite different from that of thermosetting composites, which, if heated above $T_{c 1}$, do not change very much their thermal properties when cooled down.

Irreversible changes, however, have been observed in the thermoplastic material for $T_{\text {furnace }}>450^{\circ} \mathrm{C}$ : a drastic degradation appears, with a sevenfold decrease in both alpha and kappa (the change in volumetric heat capacity is very small, however). The reversibility of thermal properties below $\sim 450^{\circ} \mathrm{C}$ in the present case means that their effective value in the fire tests for that range of temperatures cannot be provided by our flash 
technique setup, since it cannot be used for the material while at the furnace.

On the other hand, it must be noted that there are important differences between uniform heating in a furnace and heating by a flame, since the latter is much faster and very inhomogeneous spatially. This creates large temperature gradients that, in turn, bring about internal stresses that are a source of degradation; thus, in a fire resistance test this process should begin at temperatures lower than in the case of furnace heating. This means in practice that our objective should be to obtain effective parameters that provide a good simulation of the fire test, rather than aiming at properties of the material measured for quasiestatic, homogeneous heating, that may be not useful for a sample whose temperature is extremely inhomogeneous and changes very fast.

\section{THERMAL CHARACTERIZATION OF THERMOPLASTICS UNDER FIRE}

The measurements reported in the previous sections have established the reversibility of the thermal properties of the thermoplastic material for homogeneous and slow heating below $\sim 450^{\circ} \mathrm{C}$, and have not found critical temperatures as those exhibited by thermosetting materials. However, this kind of process is quite different from the fast and inhomogeneous heating experimented by a material exposed to a fire, and therefore it becomes necessary to perform a test with a real fire and analyze the behavior of the material in situ. Since the evolution of the slope of the temperature versus time profiles provides information on critical temperatures, ${ }^{5,11}$ this test could provide realistic values for $T_{c 1}, T_{c 2}$ in thermoplastics. The test could give also valuable information to calculate thermal parameters at temperature ranges above $150^{\circ} \mathrm{C}$, where step heating experiments were not well fitted by the room temperature values (see Figure 3).

The fire test was carried out at the AIRBUS facilities in Getafe (Spain), according to the ISO 2685:1998 standard. The dimensions of the sample were $600 \times 400 \times 4.5 \mathrm{~mm}$. Two infrared cameras imaged both sides of the sample during the fire test, providing surface temperature maps spatially co-registered. ${ }^{5}$ The front face camera was a FLIR A325 fitted with a band-pass interference filter (wavelength center $9565 \mathrm{~nm}$, full width at half maximum $95 \mathrm{~nm}$ ) to minimize the effect of flame emitted radiation, and was calibrated for temperatures up to $1000^{\circ} \mathrm{C}$. The rear face camera was a Sensia Caroline with a spectral range from 7 to $12 \mu \mathrm{m}$. Figure 6 shows a scheme and a photograph of the setup.
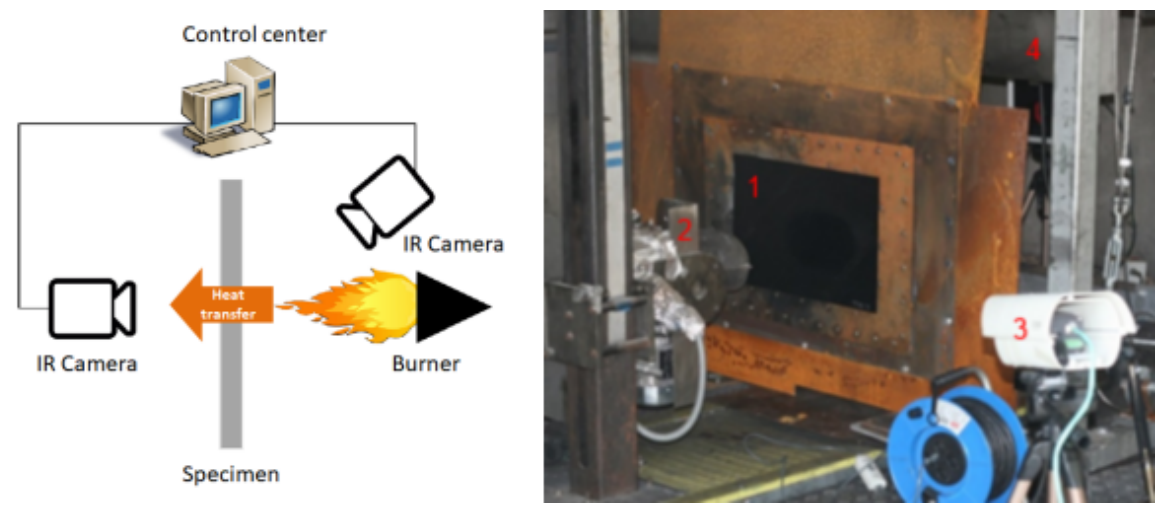

Figure 6: (Left) Scheme of the measurement setup of the fire test. Right: The full setup of the fire test: (1) Specimen, (2) Burner, (3) Front face IR camera, (4) Rear face IR camera.

Figure 7 shows the temperature maps of the front (left) and rear (right) faces at two times during the fire resistance test: while the temperature is rising, at $\mathrm{t}=22 \mathrm{~s}$ (top) and when a nearly steady state has been reached, at $\mathrm{t}=80 \mathrm{~s}$ (bottom). The flame impacted on the left side of the sample, as can be seen in the front-face images. A reflection of the burner can be seen as well on the right side, but its effect on the mapped temperature values is very small.

A striking fact is the large temperature difference between the front and rear faces. At the steady state, a thermal drop of about $540^{\circ} \mathrm{C}$ is reached for a thickness of $4.5 \mathrm{~mm}$, i.e., the temperature gradient across the plane is $\sim 120^{\circ} / \mathrm{mm}$. There is also an in-plane gradient, that can be as large as $\sim 2.5^{\circ} / \mathrm{mm}$, which explains the progressive uniformization of temperatures at the rear face, due to in-plane heat conduction in the sample. 

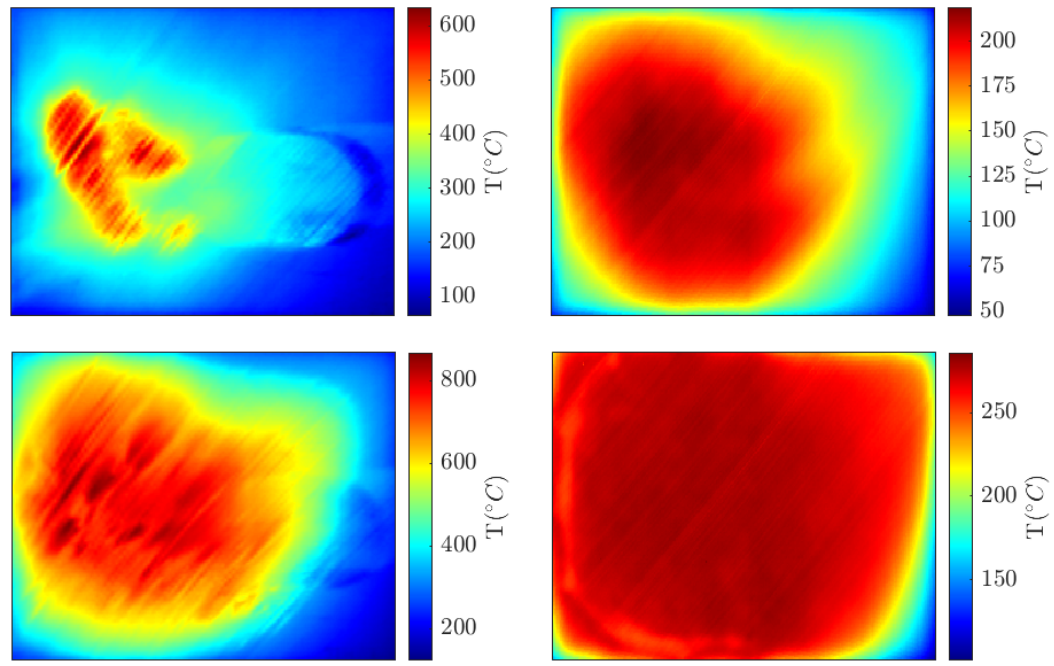

Figure 7: Temperature maps of the front (left) and rear (right) faces at two times during the fire resistance test, $\mathrm{t}=22$ $\mathrm{s}(\mathrm{top})$ and $\mathrm{t}=80 \mathrm{~s}$ (bottom).

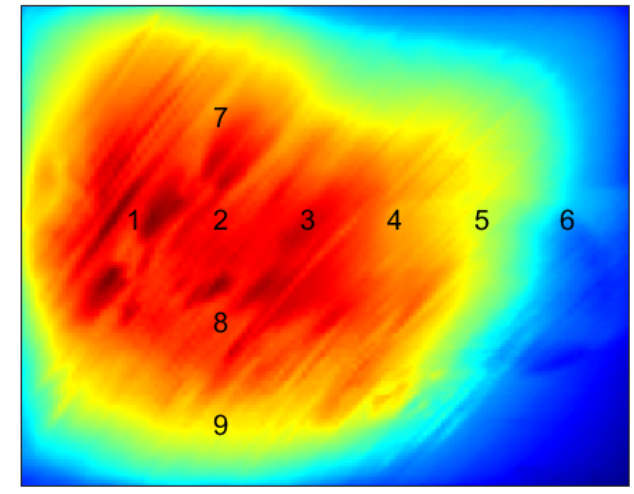

Figure 8: Location on the front face of the points for the thermal profiles of Figures 9 and 11.

The relative low temperature of the rear face explains that, contrary to the usual result in thermoset composites, no bubble-like degraded zones were found.

\subsection{Thermal profiles: front face}

More detailed information can be obtained from the time profiles of temperature during the experiment. The temperature vs time evolution of several points on the front side of the sample (whose positions are shown in Figure 8) is plotted in Figure 9.

After the start of fire application, the temperature increases more or less uniformly, although transitory maxima of temperature are observed at different times $(\approx 40,60,100 \mathrm{~s})$. Our working hypothesis is they are caused by the appearance of volatiles produced by evaporation during the melting of the resin. These volatile pockets grow and are expelled as the material degrades, repeating the process from time to time, producing bubbles where the most superficial layers of the sample lose adherence with those below, and their temperature increases due to the reduced capacity to evacuate heat to the rear side. However, this effect does not significantly affect either the thermal characterization or the validation of the thermal model.

There is a more relevant effect that can be seen in all the profiles from the hottest points $(1,2,3,8$, and 9): a sudden increase in temperature when $\mathrm{T}$ exceeds $\sim 300^{\circ}$. A more detailed study using the time derivative of $\mathrm{T}$ shows that there are in fact two abrupt changes in slope; one around $300^{\circ} \mathrm{C}$ (a point of inflection in the $\mathrm{T}(\mathrm{t}$ ) 
graph) and another around $370^{\circ} \mathrm{C}$, as can be seen in Figure 10 (the estimated error in these values is around $3 \%$ in K). These are the points of extreme slope (letting aside the maxima at the sudden turning on and off of the fire, and the long-term minimum when reaching the stationary temperature) and thus they mark significant features of the behavior of the material. In particular, they are probably related to the melting point, that, as mentioned in the Introduction, is situated between $\approx 343-380^{\circ} \mathrm{C}$ for the PAEK family resins.
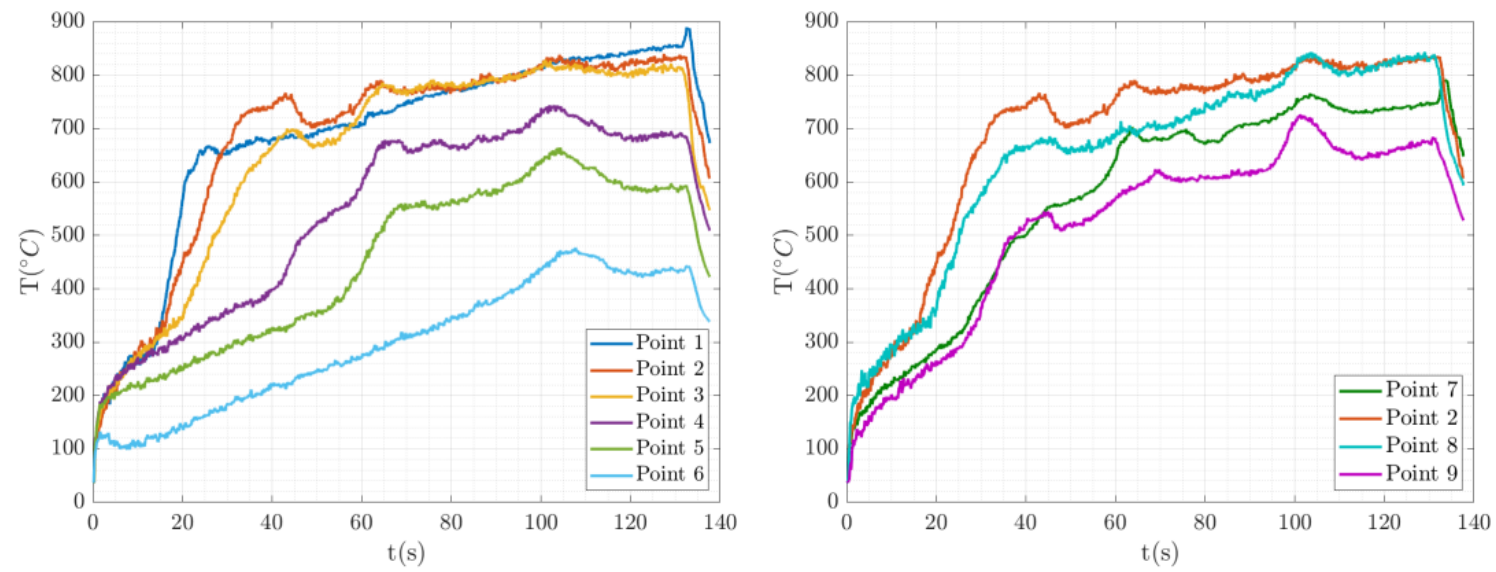

Figure 9: Thermal profiles for points at the front face: left, along the horizontal axis; right, along the vertical axis. The fire ends at $137 \mathrm{~s}$.
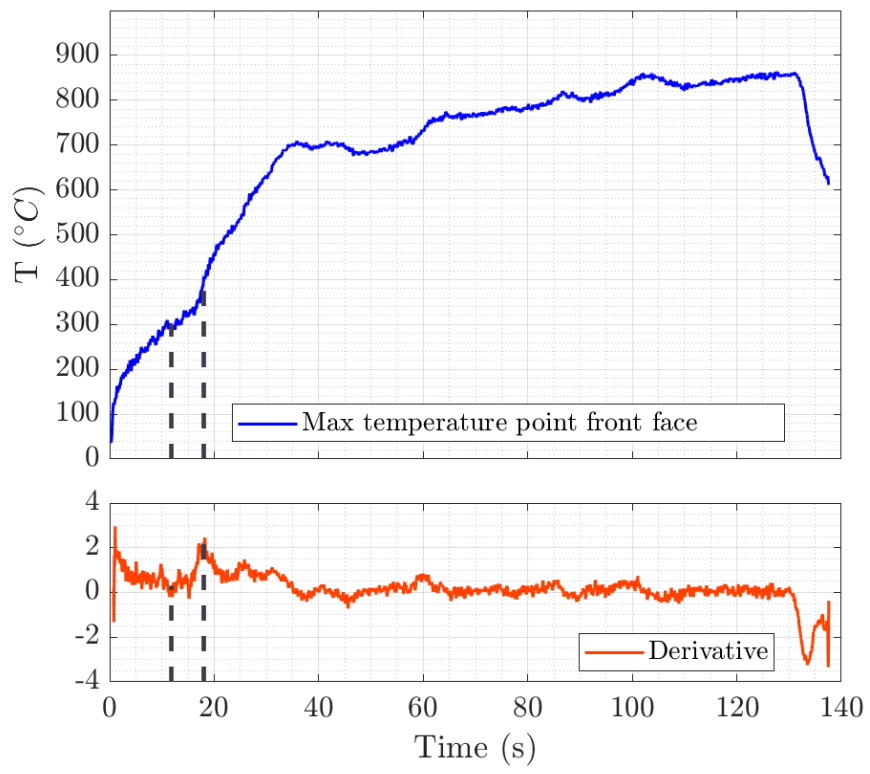

Figure 10: Temperature vs time for the hottest point in the front face of the fire test. The time derivative of $\mathrm{T}$ has been plotted in order to find the points of extreme slope. There are two reproducible features at $T \sim 300^{\circ}$ (minimum slope, blue vertical line) and $T \sim 370^{\circ}$ (maximum slope, red vertical line).

\subsection{Thermal profiles: rear face}

The same points marked in Figure 8 have also been studied on the cold side. The evolution of temperature is more regular, without the transitory maxima found in the front face, as expected since at the lower temperatures of the rear face resin does not melt and no bubbles with volatile emission appear. The profiles evolve uniformly 
up to a nearly stationary regime, although a decrease in temperature can also be seen from $100 \mathrm{~s}$ onwards. A probable explanation is the already mentioned loss of adherence between layers near the front face, due to emission of volatile gases at high temperatures, that increases overall thermal isolation between both faces of the sample.
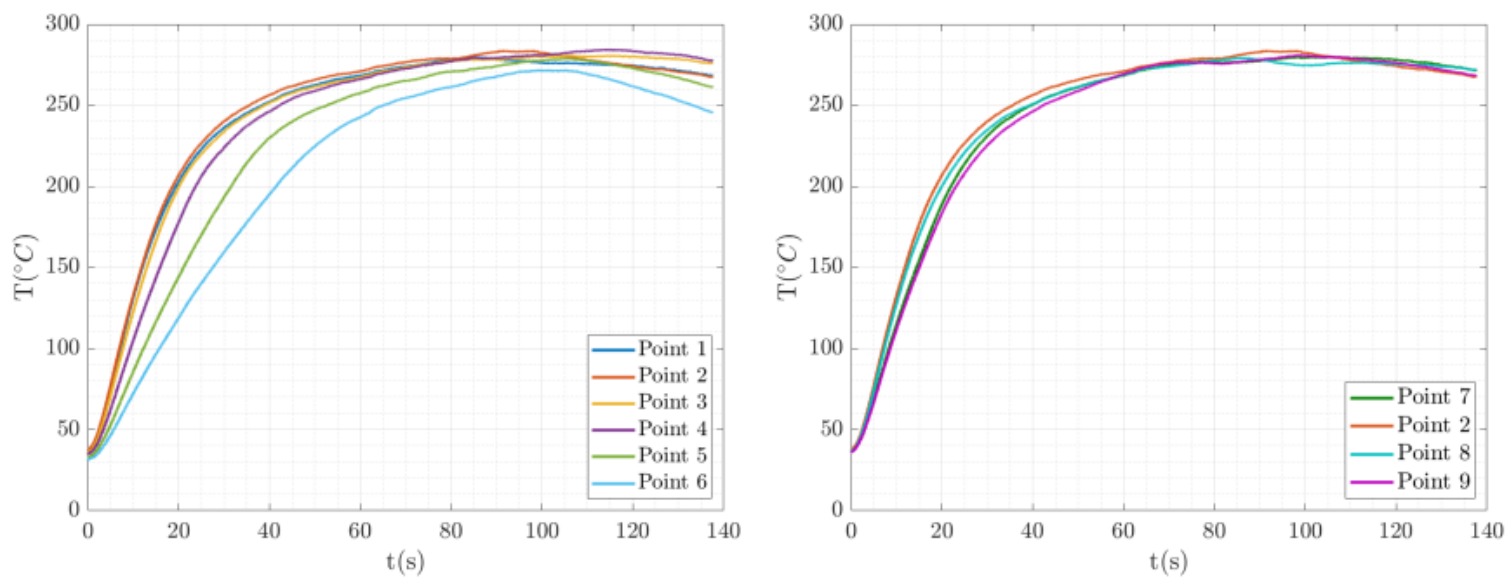

Figure 11: Thermal profiles for points at the rear face: left, along the horizontal axis; right, along the vertical axis. The fire ends at $137 \mathrm{~s}$.

\section{CHARACTERIZATION AND SIMULATION}

The study of temperature profiles in the previous section found a maximum in the slope of $\mathrm{T}$ vs $\mathrm{t}$ at a temperature of around $370^{\circ}$, that corresponds approximately with the expected melting temperature. Although it is expected that the complete chemical degradation of the material is not reached until $\approx 450-500^{\circ}$, as explained in Section ??, there are no additional marked features in the slope of $\mathrm{T}$ vs t. To keep the model simple, it will be assumed that, regarding the effective thermal parameters in the fire test, the material reaches a maximum degradation at $T_{c 2}=370^{\circ}$. Besides, the fact that step heating experiments have shown that room temperature parameters do not fit the thermal behavior above $150^{\circ} \mathrm{C}$, suggests, as explained in Section 2.2 , that some degree of thermal degradation begins above that temperature, although it does not appear in the furnace heating experiments because it is reversible. Therefore, we will propose the initial hypothesis, yet to be validated, that effective thermal properties in the fire test begin to change at $T_{c 1} \approx 150^{\circ} \mathrm{C}$ and complete their degradation at $T_{c 2} \approx 370^{\circ} \mathrm{C}$. Within this interval lies the inflection point at $T_{i} \approx 300^{\circ} \mathrm{C}$, that may mark a with a probable change in their dependence on temperature.

\subsection{Finite element model}

With these constraints, and assuming for simplicity linear dependence on temperature, several values of the thermal parameters have been proposed and used to fit the experimental results of the fire test with a finite element model (FEM). The model uses the proposed thermal parameters as input, as well as the experimental distribution of temperatures at the front face as a function of time, and produces as output the predicted distribution of temperatures in all points of the sample, in particular, at the rear face, also as a function of time. Values at room temperature and up to $T_{c 2}=150^{\circ} \mathrm{C}$ are those obtained by the flash method as explained in section 2.1 , whereas those at $T_{i}=300^{\circ} \mathrm{C}$ and $T_{c 2}=370^{\circ} \mathrm{C}$ have been varied systematically to find the best agreement between prediction and experiment.

Values that provided the best agreement are shown in Table 1, with their dependence on temperature plotted in Figure 12.

An example of simulation of the fire test using these data is shown in Figure 13, for a point at the hottest region of the sample. The agreement of the simulation results is quite good, with an error below $3 \%$ in K. However, 


\begin{tabular}{|c|c|c|c|}
\hline & $\mathrm{T} \leq 150^{\circ} C$ & $\mathrm{~T}=300^{\circ} C$ & $\mathrm{~T} \geq 370^{\circ} C$ \\
\hline$\kappa[\mathrm{W} / \mathrm{m} \cdot \mathrm{K}]$ & 0.77 & 0.32 & 0.04 \\
\hline$\rho \cdot C_{p}\left[\mathrm{~J} / \mathrm{m}^{3} \cdot \mathrm{K}\right.$ & $1.36 \cdot 10^{6}$ & $1.12 \cdot 10^{6}$ & $1.00 \cdot 10^{6}$ \\
\hline$\alpha\left[\mathrm{m}^{2} / \mathrm{s}\right]$ & $5.6 \cdot 10^{-7}$ & $2.8 \cdot 10^{-7}$ & $0.4 \cdot 10^{-7}$ \\
\hline
\end{tabular}

Table 1: Effective thermal parameters of thermoplastic at different temperatures.
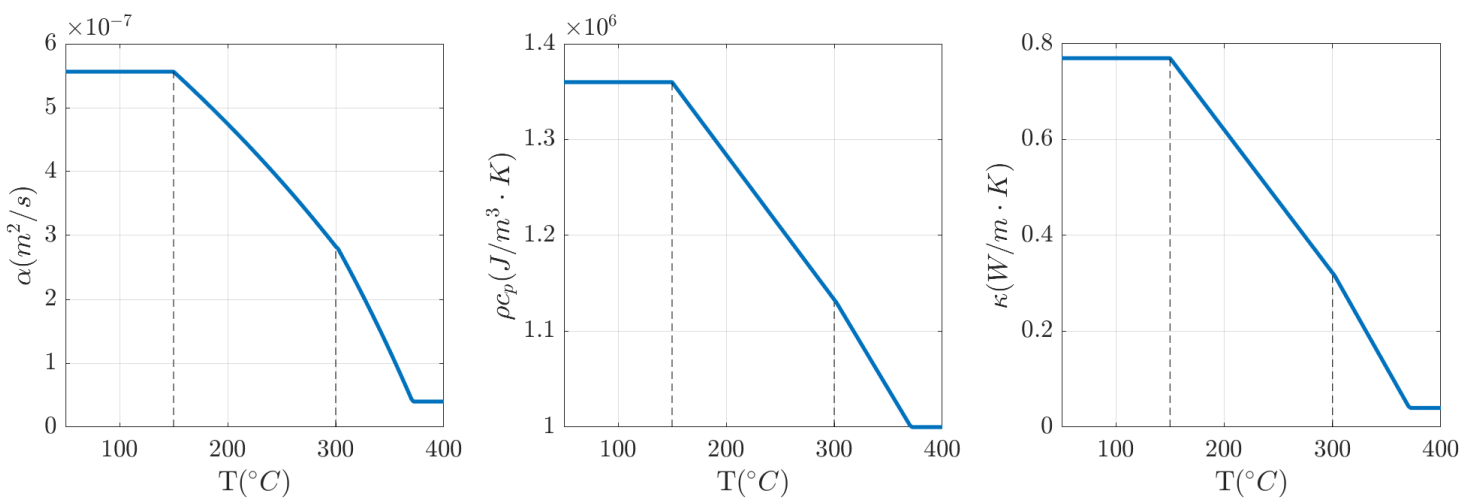

Figure 12: Proposed effective values as a function of temperature of thermal diffusivity (left), volumetric heat capacity (center), and thermal conductivity (right).

it should be borne in mind that the present simulation cannot reproduce some effects, like those derived from local delaminations, internal bubbles of volatiles, etc, that are probably responsible for the transitory maxima found in Figure 9. This explains discrepancies between calculation and experimental profile in the first stage of the fire test (up to, approximately, $\mathrm{t}=60 \mathrm{~s}$ ). In a similar way, the cooling down of the experimental profile in the rear face after $100 \mathrm{~s}$ is probably caused the loss of adherence between layers due to the emission of volatiles (see Section 4.2), another effect that cannot be reproduced by the simulation, which explains the discrepancy at the last stage of the fire test.

The FEM model makes it possible also to simulate the degradation of the specimen through its thickness.
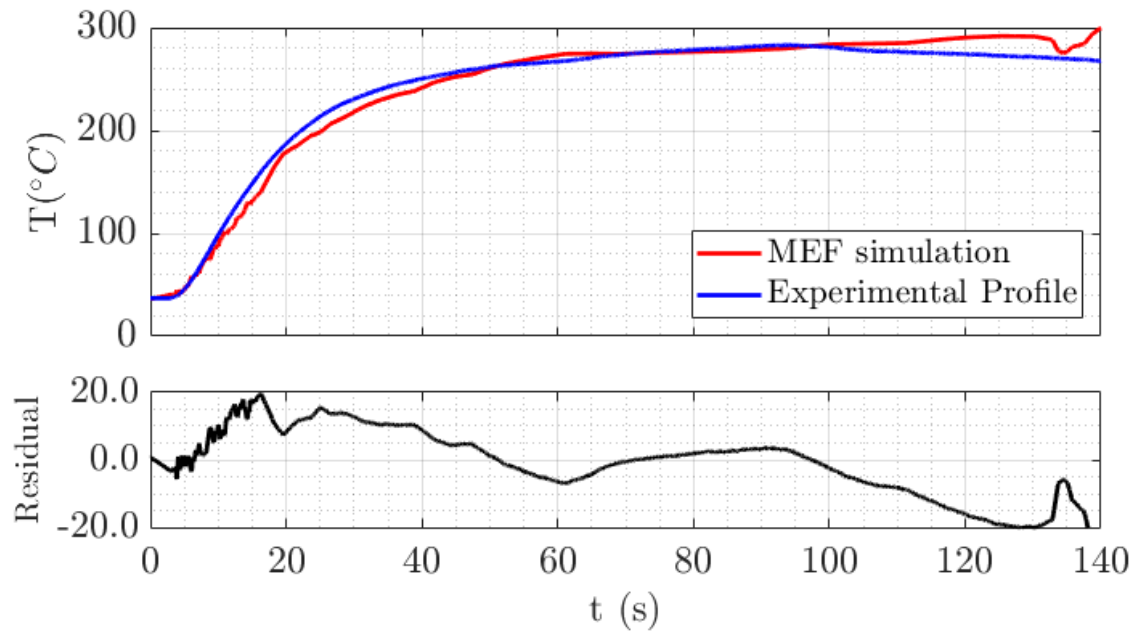

Figure 13: Comparison between the temperature profiles obtained from the experimental and simulation tests. The adjustment obtained is quite good using the parameters proposed in the previous table. The simulation error does not exceed $3 \%$ in $\mathrm{K}$. The probable explanation for the separation between both curves for temperatures higher than $100^{\circ} \mathrm{C}$ is the apparition of small gas bubbles produced by resin evaporation. 

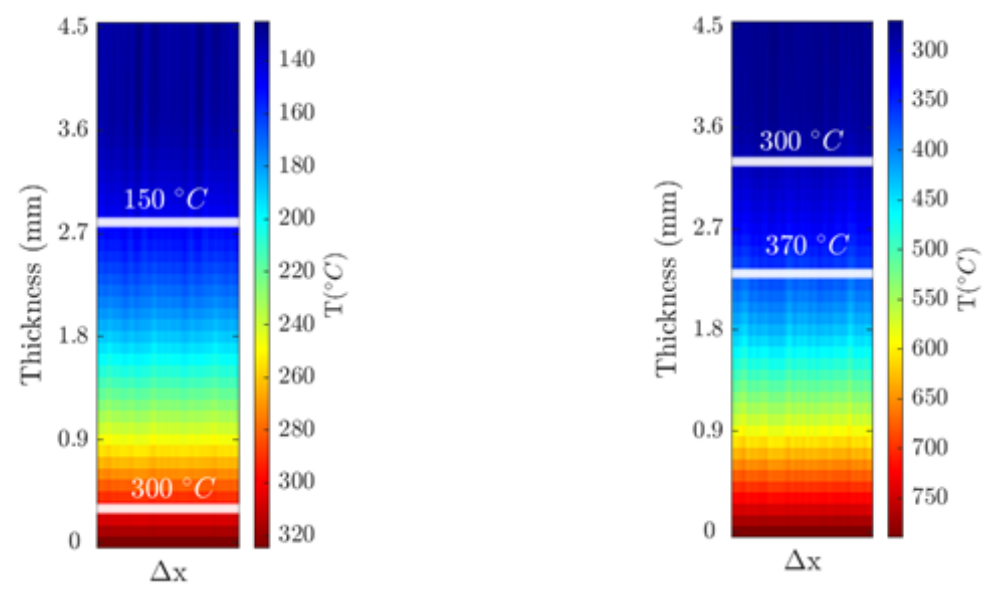

Figure 14: Simulation of temperature distribution through the thickness for two instants after fire application on front face: left, at $\mathrm{t}=15 \mathrm{~s}$, right at $\mathrm{t}=80 \mathrm{~s}$. The state of degradation can be appreciated in the color scale. The region of specimen where $T>370^{\circ} \mathrm{C}$ can be considered as fully degraded

Figure 14 shows the inhomogeneous degradation of specimen $80 \mathrm{~s}$ after fire application due to the high gradient of temperatures across the thickness. At an instant close to the start of heating $(15 \mathrm{~s}$, left), already most of the material is above $T_{c 1}=370^{\circ} \mathrm{C}$. After $80 \mathrm{~s}$ of fire application, roughly one-half of the specimen thickness has exceeded $T_{c 2}=370^{\circ} \mathrm{C}$. That means that only one-half of the specimen thickness is not fully degraded and retains some mechanical resistance.

\subsection{Validation of thermal parameters at intermediate temperatures}

The set of thermal parameters proposed in the previous section have been used also to simulate the step test that previously was not correctly fitted with the room temperature parameters (Figure 3). The results are shown in Figure 15. Matching between experimental and simulated profiles is now quite good, with negligible differences, much less than $1 \%$ in $\mathrm{K}$. This suggests that at least part of the larger discrepancies found in the fire tests (Figure 13 are due to phenomena not simulated by our model, such as flame fluctuations, emission of volatiles from bubbles, loss of adherence between layers, etc.

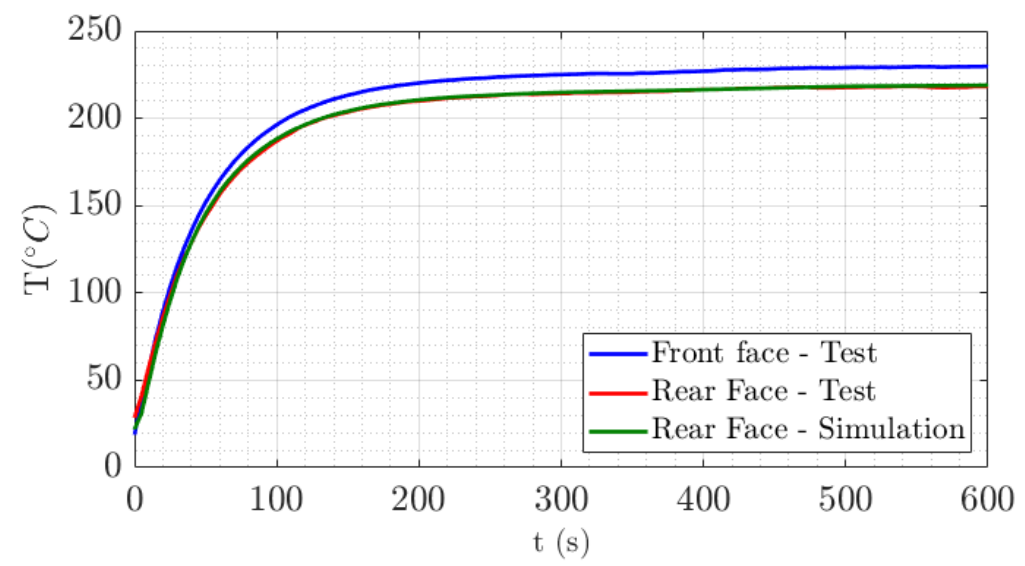

Figure 15: Profiles of the thermal evolution for the heater test where the experimental hot face and cold face and the simulated cold face are plotted. 


\section{SUMMARY AND CONCLUSIONS}

A thermoplastic composite based on PAEK (Polyaryletherketone) resin has been characterized. The values of the main thermal parameters (diffusivity, conductivity, and volumetric heat capacity) have been measured at room temperature by a modified flash technique that takes into account thermal losses. Values of those parameters as a function of temperature have been proposed on the basis of experimental measurements of the evolution of temperature vs time performed on a fire test. These values have been used to feed a FEM model that uses as input the measured distribution of temperatures, as a function of time, on the face of the sample exposed to fire, and produces as output the predicted temperatures on the rear face of the sample during the fire test. Comparison of prediction and experiment has validated the proposed values of the effective thermal parameters, with differences less than $3 \%$ in $\mathrm{K}$ between experimental test and simulation, for temperatures up to $\sim 850^{\circ} \mathrm{C}$ in the front face and $\sim 260^{\circ} \mathrm{C}$ in the rear face. In step tests carried out without fire (no flame fluctuations and maximum temperature in the rear face $\sim 240^{\circ} \mathrm{C}$ ), the differences are near or below $1 \%$ in $\mathrm{K}$.

The proposed dependence of thermal parameters on temperature is as follows:

- At $\sim 150^{\circ} \mathrm{C}$, the thermal parameters begin to change, initiating the degradation process. We define this temperature as $T_{c 1}$, "first critical temperature", that coincides with the glass transition temperature $T_{g}$.

- Degradation in the parameters grows linearly with temperature from $150^{\circ} \mathrm{C}$ up to $300^{\circ} \mathrm{C}$. We define this temperature as $T_{i}$ "inflection temperature". Above $T_{i}$, the material increases the rate of degradation.

- This behavior continues up to $370^{\circ} \mathrm{C}$. From this temperature onwards, the thermal parameters maintain their values unchanged, similar to those of charcoal. We define it as $T_{c} 2$, "second critical temperature"; its value is in the range of the melting temperature $T_{m}$.

An appealing feature of the approach here proposed is that the internal temperature at any point of the sample can be simulated by the FEM model, providing thus a prediction of the degradation state across the specimen thickness for any time after fire application.

There are, however some features found in the experimental evolution of the temperature that are not explained directly by this dependence of thermal parameters on temperature, but rather by other more complex phenomena. In particular, the fluctuations of temperature observed in the front face are probably caused by gas bubbles appearing and disappearing between specimen layers due to resin evaporation. Also, the most likely explanation of the decrease in the rear face temperature observed at the final stage of the fire test is the increase of the overall thermal resistance of the material due to loss of adherence between layers.

It has been found that the material behaves very differently when steadily heated in a furnace at quasithermal equilibrium and when fire is applied on one side. While in furnace heating the thermal parameters have been found to be reversible with temperature, and almost no damage is observed up to $450{ }^{\circ} \mathrm{C}$, when submitted to fire fire the material suffers a complete degradation of its thermal and mechanical properties at $370{ }^{\circ} \mathrm{C}$. The difference can be explained by the large temperature gradient suffered by the material in tests performed under fire, which causes mechanical stress and accelerates degradation. This means that values of thermal properties for these materials determined in laboratory conditions may not be useful to predict their behavior when submitted to fire or high-temperature events in real conditions, and underlines the necessity of an approach based on the interplay of simulations and measurements in real fire tests.

\section{ACKNOWLEDGMENTS}

This work has received funding from the Clean Sky 2 Joint Undertaking (JU) under grant agreement No 864713. The JU receives support from the European Union's Horizon 2020 research and innovation programme and the Clean Sky 2 JU members other than the Union. It has been supported also by Comunidad de Madrid (Spain) - Multiannual agreement with UC3M ("Excelencia para el Profesorado Universitario" - EPUC3M14 ) - Fifth regional research plan 2016-2020.

The authors wish to acknowledge also FireLab-Airbus in Getafe (Spain) for their collaboration on the fire tests. 


\section{REFERENCES}

1. A. P. Mouritz and A. G. Gibson, Fire properties of polymer composite materials, vol. 143, Springer Science \& Business Media, 2007.

2. "Hitcomp: High temperature characterization and modelling of thermoplastic composites." https://trimis.ec.europa.eu/project/high-temperature-characterization-and-modelling-thermoplasticcomposites, 2019. Accesed 2021-03-12.

3. D. Parker, J. Bussink, H. T. van de Grampel, G. W. Wheatley, E.-U. Dorf, E. Ostlinning, and K. Reinking, "Polymers, high-temperature," in Ullmann's encyclopedia of industrial chemistry, C. Ley, ed., Wiley-VCH, 2011.

4. B. Ilschner, J. K. Keels, A. K. Dhingra, and R. L. McCullough, "Composite materials," in Ullmann's encyclopedia of industrial chemistry, C. Ley, ed., Wiley-VCH, 2011.

5. S. Sánchez-Carballido, C. Justo-María, J. Meléndez, and F. López, "A quantitative infrared imaging system for in situ characterization of composite materials in fire tests," Fire technology 53(3), pp. 1309-1331, 2017.

6. C. B. Justo María, Caracterización térmica y de defectos en materiales compuestos mediante imagen infrarroja. Modelización física, sistema experimental y técnicas de reducción de datos. PhD thesis, Universidad Carlos III de Madrid. Departamento de Física, Sept. 2018.

7. W. Parker, R. Jenkins, C. Butler, and G. Abbott, "Flash method of determining thermal diffusivity, heat capacity, and thermal conductivity," Journal of applied physics 32(9), pp. 1679-1684, 1961.

8. A. Degiovanni, "Diffusivité et methode flash," Rev. Gén. Therm., Fr. 32(185), pp. 420-442, 1977.

9. M. Mullins, D. Liu, and H.-J. Sue, "Mechanical properties of thermosets," in Thermosets: structure, properties, and applications, Q. Guo, ed., pp. 35-68, Elsevier, 2018.

10. P. Moulinie, R. Paroli, Z. Wang, A. Delgado, A. Guen, Y. Qi, and J.-P. Gao, "Investigating the degradation of thermoplastics by thermogravimetry-fourier transform infrared spectroscopy (tg-ftir)," Polymer testing 15(1), pp. 75-89, 1996.

11. S. Sánchez-Carballido, C. Justo-María, J. Meléndez, and F. López, "Measurement of the thermal parameters of composite materials during fire tests with quantitative infrared imaging," Fire technology 54(1), pp. 313$333,2018$. 